\title{
Identification and Management of Hepatitis C Patients in Primary Care Clinics
}

Thomas M. Shehab, M.D., Mauricio Orrego, M.D., Renu Chunduri, M.D., and Anna S. F. Lok, M.D. Divisions of Gastroenterology and General Internal Medicine, Department of Internal Medicine, University of Michigan Health System, Ann Arbor, Michigan

OBJECTIVE: Previous survey-based research suggested that hepatitis $\mathrm{C}$ patients receive suboptimal care in primary care settings. The aim of our study was to define the actual level of care hepatitis $\mathrm{C}$ patients receive in primary care clinics.

METHODS: Medical records of 229 hepatitis C antibodypositive (group 1), 229 hepatitis $\mathrm{C}$ antibody-negative (group 2), and 229 patients not tested for hepatitis C antibody (group 3) were reviewed to assess the indications for hepatitis $\mathrm{C}$ testing and the subsequent management and referral of hepatitis $\mathrm{C}$ antibody-positive patients diagnosed in primary care clinics. In addition, the compliance of primary care physicians with hepatitis $\mathrm{C}$ screening and testing guidelines was assessed.

RESULTS: Only $16 \%$ of group 1 and $10 \%$ of group 2 patients were tested for hepatitis $\mathrm{C}$ based on physician-identified risk factors. Only $1 \%$ of group 3 patients had documented discussion of hepatitis $C$ risk factors during their initial visit with a primary care physician. The majority of hepatitis $\mathrm{C}$ antibody-positive patients was appropriately evaluated in primary care clinics, and most (77\%) hepatitis C RNApositive patients with elevated liver enzymes were referred for subspecialty care. Of the 59 patients who underwent liver biopsy, $40 \%$ had bridging fibrosis or cirrhosis.

CONCLUSIONS: Hepatitis $\mathrm{C}$ testing is rarely initiated in primary care clinics based on physician-identified risk factors. Interventions should be developed to optimize early diagnosis of hepatitis $\mathrm{C}$ as significant liver disease may be present despite the absence of symptoms. (Am J Gastroenterol 2003;98:639-644. () 2003 by Am. Coll. of Gastroenterology)

\section{INTRODUCTION}

Approximately four million Americans have antibodies to the hepatitis $\mathrm{C}$ virus (anti-HCV), 74\% of whom are chronically infected (1). Chronic hepatitis $\mathrm{C}$ infection is the most common cause of end-stage liver disease and is the leading indication for liver transplantation in the United States (2). The economic impact of chronic hepatitis $\mathrm{C}$ infection in the United States is projected to exceed $\$ 1$ billion per year in direct medical costs between the years 2010 and 2019 (3). The overall scope of this disease makes it a common and important challenge to both primary care physicians and subspecialists.

There are numerous potential benefits to diagnosing hepatitis $\mathrm{C}$ in the presymptomatic phase. Diagnosis of hepatitis $\mathrm{C}$ provides the patient with the opportunity to be counseled regarding behaviors that may transmit the infection to others. Diagnosis also allows the health care provider to educate the patient regarding behaviors that may hasten the progression of liver disease (such as alcohol intake), and provide the patient with appropriate preventive services (hepatitis A vaccination) $(4,5)$. Finally, diagnosis allows the patient to be evaluated for hepatitis $\mathrm{C}$ therapy. Over the last decade, the efficacy of hepatitis $\mathrm{C}$ therapy has improved significantly. Hepatitis $\mathrm{C}$ therapy leads to sustained clearance of the virus in approximately $50 \%$ of all patients who are treated and may slow or prevent the progression of hepatitis C-related liver disease (6-9). Given the benefits of early diagnosis, it is important to ensure that health care providers are equipped to identify individuals who are at risk for hepatitis $\mathrm{C}$ and to provide adequate care for those who test positive.

Previous surveys of primary care physicians demonstrated a number of potential knowledge deficits that may impact both the diagnosis and subsequent care of patients with hepatitis C. Despite recommendations to ask all patients about hepatitis C risk factors (5), only 59\% of primary care physicians reported doing so routinely $(10,11)$. In addition, only $68 \%$ of primary care physicians reported routinely testing outpatients with elevated liver enzyme levels for hepatitis C (12). In these same studies, approximately one-third of primary care physicians reported they do not routinely refer anti-HCV-positive patients with elevated liver enzyme levels to a subspecialist. These findings suggest that a significant proportion of patients with hepatitis $\mathrm{C}$ may remain undiagnosed despite receiving routine health care. Because less than $1 \%$ of primary care physicians reported prescribing hepatitis $C$ therapy (10), the vast majority of hepatitis $C$ patients who are not referred will not have access to therapy. If self-reported practice mirrors reality, hepatitis $C$ patients may receive suboptimal care. To date, there has been no report on the actual care hepatitis $\mathrm{C}$ patients received in primary care clinics. 
The primary aims of this study were to determine: 1) the indications for hepatitis $\mathrm{C}$ testing in primary care clinics, 2) the subsequent management and referral of hepatitis $\mathrm{C}$ antibody-positive patients diagnosed in primary care clinics, and 3) primary care physicians' compliance with guidelines for hepatitis $\mathrm{C}$ screening and testing. In addition, we describe the extent of hepatitis C-related liver disease in the cohort of patients who underwent further evaluation.

\section{MATERIALS AND METHODS}

\section{Setting}

This study was undertaken after approval by the University of Michigan Institutional Review Board. The University of Michigan primary care system (family medicine, general internal medicine, pediatrics, and combined medicine/pediatric clinics) includes 26 community-based primary care clinics and seven primary care clinics located on the University Hospital campus. Annually, the primary care system handles approximately 900,000 outpatient visits.

\section{Subjects}

The University of Michigan's clinical laboratory database was used to identify all patients above the age of $18 \mathrm{yr}$ seen in a primary care clinic, who tested positive for hepatitis $C$ antibody (anti-HCV) using enzyme immunoassay (EIA) between January 1, 1998, and December 31, 1999 (group 1). Two control groups were studied. The first control group included patients who tested negative for anti-HCV during the same period, matched for age, sex, and clinic site (group 2). The second control group were patients matched for age, sex, and clinic site, who were not tested for hepatitis C (group 3).

\section{Data Collection}

Each patient's electronic notes, on-site clinic charts, laboratory results, and records of clinic attendance were reviewed. Information on sociodemographics, indication for hepatitis C testing, laboratory use of hepatitis C-related tests, documentation of referral, and inquiry into hepatitis $\mathrm{C}$ risk factors was entered on a data abstract form.

Three physicians participated in the chart review and data abstraction process. To standardize data abstraction, the first 50 charts were reviewed individually by all three physicians. The data forms were compared, and differences were found in four $(8 \%)$ forms. In all but one case, the difference involved a single data field. These differences were resolved through a joint discussion among the three reviewers. Of the remaining charts, $28 \%$ were reviewed by at least two reviewers, and the rate of discordance was less than $1 \%$.

\section{Indication for Hepatitis C Testing}

Indication for hepatitis $C$ testing for group 1 and 2 patients was based on explicit documentation of the actual reason(s) the primary care physicians ordered hepatitis $\mathrm{C}$ testing on the date the tests were performed.

\section{Laboratory Testing}

To determine if additional HCV testing was ordered by primary care physicians, computerized laboratory results on all $\mathrm{HCV}$ tests up to $1 \mathrm{yr}$ from the date of initial positive anti-HCV testing by EIA were searched. To differentiate between further testing ordered by primary care physicians versus reflex confirmatory tests initiated by the hospital laboratory, only tests ordered after the anti-HCV (EIA) result had been reported were included.

To determine if abnormal liver enzyme levels triggered hepatitis $\mathrm{C}$ testing and if patients who tested positive for anti-HCV were evaluated for liver disease, computerized laboratory results on liver biochemistries for the period $1 \mathrm{yr}$ before and $1 \mathrm{yr}$ after the initial anti-HCV test of group 1 patients were searched.

\section{Referral}

Referral for subspecialty care was determined by reviewing primary care physicians' notes for documentation of referral and searching the health system appointment database for any scheduled gastroenterology/liver clinic appointments within $1 \mathrm{yr}$ of the initial anti-HCV testing. A patient was considered to be "referred" if the primary care physician described a referral plan or an appointment in the gastroenterology/liver clinic was made, regardless of actual attendance in the subspecialty clinic. Within our health system, approximately $95 \%$ of subspecialty care of hepatitis C patients are provided by hepatologists, and the remaining $5 \%$ by gastroenterologists and infectious disease specialists.

\section{Extent of Liver Disease}

Biochemical, virological, and histological data were collected on all patients who were seen in gastroenterology/ hepatology clinics. Histological data were obtained by reviewing pathology reports. All liver biopsies were read by one of two pathologists.

\section{Compliance With Screening Recommendations}

The majority of the anti-HCV testing was not performed during the patients' first visit to the health system. To determine if there was any delay in identification of patients who were at risk of hepatitis $\mathrm{C}$, medical records of the initial visit were reviewed for documentation of inquiry into hepatitis $\mathrm{C}$ risk factors. The risk factors searched for included: injection drug use (IDU), blood transfusion before 1992, use of intranasal cocaine, multiple sexual partners, occupational exposure to blood or contaminated needles or instruments, history of sexually transmitted disease, birth to mother with hepatitis $\mathrm{C}$, and history of acute hepatitis. The first visit was identified through the health system database. Given the relatively recent discovery of hepatitis $\mathrm{C}$, only first visits that occurred after January 1, 1993, were reviewed.

\section{Data Analyses}

All data were entered into a Microsoft Excel spreadsheet and analyzed using the SPSS 9.0 (SPSS, Chicago, IL) sta- 
Table 1. Demographics of Patients Undergoing Anti-HCV (EIA) Testing in Primary Care Clinics

\begin{tabular}{|c|c|c|c|}
\hline & Group 1 & Group 2 & Group 3 \\
\hline & $\begin{array}{c}\text { Anti-HCV+ } \\
(\%)\end{array}$ & $\begin{array}{c}\text { Anti-HCV- } \\
(\%)\end{array}$ & $\begin{array}{c}\text { Not Tested } \\
(\%)\end{array}$ \\
\hline Total & 229 & 229 & 229 \\
\hline \multicolumn{4}{|l|}{ Gender } \\
\hline Male & 128 (56) & $128(56)$ & $128(56)$ \\
\hline Female & $101(44)$ & $101(44)$ & $101(44)$ \\
\hline \multicolumn{4}{|l|}{ Race } \\
\hline White & $176(77)$ & $175(76)$ & $172(75)$ \\
\hline Black & $21(9)$ & $23(10)$ & $22(10)$ \\
\hline Asian & $9(4)$ & $12(5)$ & $7(3)$ \\
\hline Hispanic & $3(1)$ & $1(1)$ & $4(2)$ \\
\hline Unknown & $20(9)$ & $18(8)$ & $24(10)$ \\
\hline \multicolumn{4}{|l|}{ Age (yr) } \\
\hline Mean \pm SD & $44.1 \pm 8.7$ & $42.9 \pm 9.0$ & $43.7 \pm 8.4$ \\
\hline Range & $22-77$ & $21-78$ & $19-74$ \\
\hline \multicolumn{4}{|l|}{ Ordering clinic } \\
\hline Internal medicine & $152(67)$ & $150(66)$ & $154(67)$ \\
\hline Family medicine & $75(32)$ & $76(33)$ & $71(31)$ \\
\hline Medicine/pediatrics & $2(1)$ & $3(1)$ & $4(2)$ \\
\hline
\end{tabular}

tistics package. Comparisons between groups 1, 2, and 3 were made using simple $t$ test.

\section{RESULTS}

During the study period, 16,383 anti-HCV (EIA) tests were performed on 13,669 patients in our clinical laboratory. Of these, 7,450 tests were ordered in primary care clinics on patients $>18$ yr old. Thus, anti-HCV (EIA) test was ordered for approximately $0.8 \%$ of primary care visits.

\section{Demographics}

The demographics of groups 1, 2, and 3 were similar (Table $1)$.

\section{Indications for Hepatitis C Testing}

The indications for hepatitis $C$ testing are shown in Table 2. Nearly all patients in both group $1(217,95 \%)$ and group 2 $(219,96 \%)$ had a documented indication for hepatitis C testing.

Approximately 20\% (44 of 229) of patients in group 1 had more than one indication for hepatitis $\mathrm{C}$ testing. The single most common indication for hepatitis $\mathrm{C}$ testing in group 1 patients was a prior diagnosis of hepatitis $\mathrm{C}$. Most of the patients who had a previous diagnosis of hepatitis $\mathrm{C}$ were diagnosed at the time of blood donation. None of the patients who had a previous diagnosis of hepatitis $\mathrm{C}$ had undergone evaluation or treatment for hepatitis C.

When the patients with a previous diagnosis of hepatitis $\mathrm{C}$ were excluded, the most common indications for hepatitis $\mathrm{C}$ testing were abnormal liver enzymes (26\%), history of or risk factor for hepatitis B (14\%), patient request (11\%), and history of IDU (11\%). Our clinical laboratory provides a "hepatitis screening panel," which includes tests for hepatitis A, B, and C. Physicians who choose the "hepatitis
Table 2. Indications for Anti-HCV (EIA) Testing in Primary Care Patients (Expressed as Percentage)

\begin{tabular}{|c|c|c|}
\hline & Group 1 & Group 2 \\
\hline & Anti-HCV+ & Anti-HCV- \\
\hline Total & 229 & 229 \\
\hline \multicolumn{3}{|l|}{ Indications for testing } \\
\hline \multicolumn{3}{|l|}{ Risk factors } \\
\hline IDU & 11 & 1 \\
\hline Transfusion before 1992 & 3 & 5 \\
\hline STD or multiple sexual partners* & 3 & 3 \\
\hline Cocaine use & 2 & 1 \\
\hline Any of the above & 16 & 10 \\
\hline \multicolumn{3}{|l|}{ Liver disease } \\
\hline Abnormal liver enzymes & 26 & 31 \\
\hline $\begin{array}{l}\text { History of acute hepatitis or } \\
\text { abnormal liver enzymes }\end{array}$ & 8 & 6 \\
\hline $\begin{array}{l}\text { Signs or symptoms attributed to } \\
\text { liver disease }\end{array}$ & 3 & 4 \\
\hline Any of the above & 35 & 40 \\
\hline \multicolumn{3}{|l|}{ Other } \\
\hline Previous diagnosis of hepatitis $\mathrm{C}$ & 26 & 0 \\
\hline $\begin{array}{l}\text { Patient requested hepatitis } \mathrm{C} \\
\text { testing }\end{array}$ & 11 & 17 \\
\hline $\begin{array}{l}\text { History of or risk factors for } \\
\text { hepatitis B }\end{array}$ & 14 & 34 \\
\hline
\end{tabular}

screening panel" for evaluation of hepatitis B also receive hepatitis $\mathrm{C}$ test results.

Among the patients in group 2, the most common indications for hepatitis $\mathrm{C}$ testing were abnormal liver enzymes (31\%) and history of or risk factor for hepatitis B (34\%).

Very few patients in either group were tested because of physician-identified risk factors for hepatitis C: $16 \%$ in group 1 and $10 \%$ in group 2 .

\section{Laboratory Evaluation of Group 1 Patients}

Our health system laboratory automatically confirms positive anti-HCV (EIA) test results. During the first 8 months of the 24-month study period, recombinant immunoblot assay was performed, whereas in the subsequent 16 months, qualitative polymerase chain reaction (PCR) assay for hepatitis $\mathrm{C}$ virus RNA was performed. Of the 229 anti-HCV-positive patients, 97 had reflex recombinant immunoblot assay, whereas 132 had reflex PCR assay. Hepatitis C genotyping was ordered in three (1.2\%) anti-HCV-positive patients.

Repeat testing for anti-HCV by EIA was requested on 12 (5\%) patients, all of whom had negative recombinant immunoblot assay or PCR result during reflex testing initiated by the hospital laboratory.

The majority (150 of $229,66 \%)$ of the patients were tested for ALT on or before the day of the anti-HCV testing. Of the 79 patients who had not been tested, 52 (66\%) had ALT testing ordered by the primary care physician during the year after the anti-HCV test, 39 of whom had detectable HCV RNA. For the remaining 27 anti-HCV-positive patients who did not have liver biochemistries tested, 15 were PCR positive and 13 were referred. Forty-four patients had 


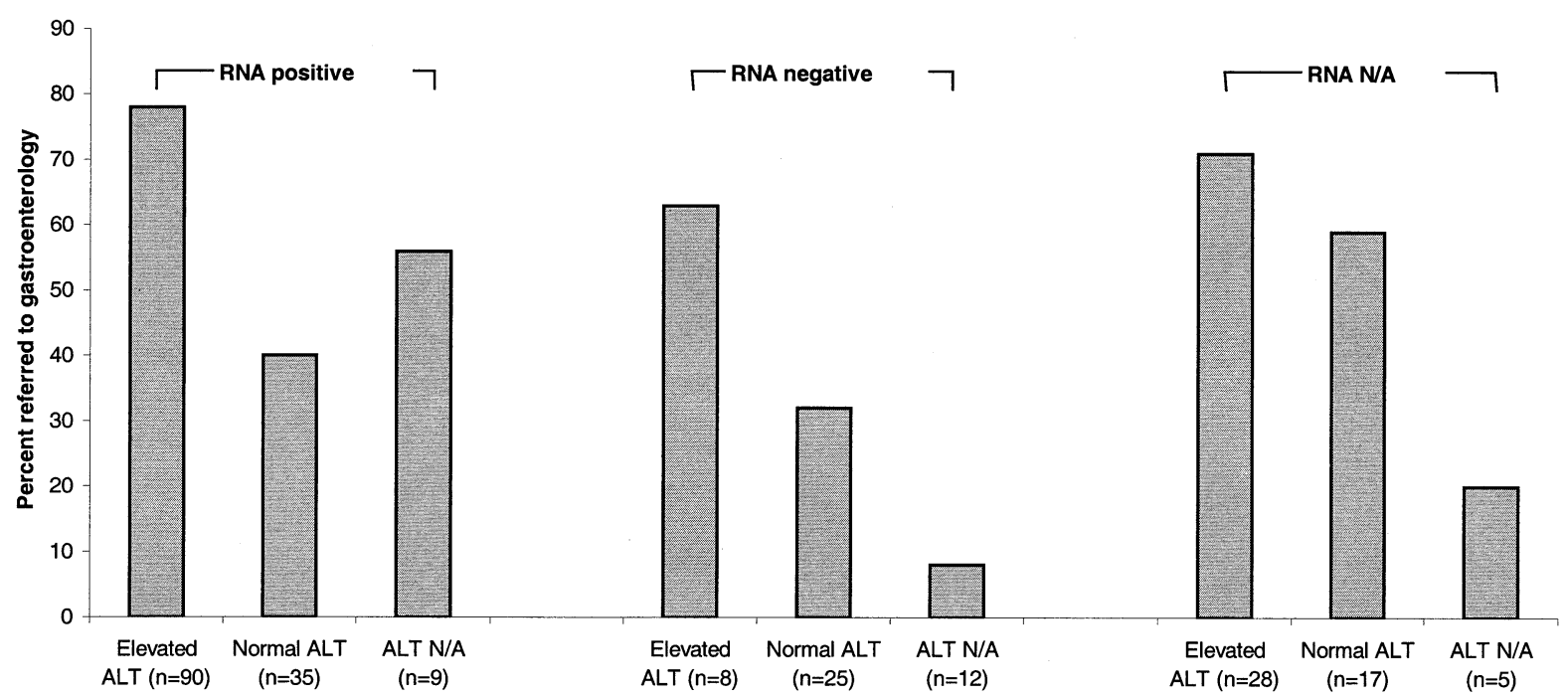

Figure 1. Referral of hepatitis $\mathrm{C}$ antibody-positive (EIA) primary care patients to gastroenterology/hepatology clinic $(\mathrm{n}=229$ patients). N/A $=$ not available.

detectable HCV RNA and normal ALT level, nine had normal ALT on repeat testing during the subsequent year and were not referred, 14 were referred for subspecialist care, and the other $21(48 \%)$ patients had no further testing or referral.

\section{Referral of Group 1 Patients}

Overall, 139 (59\%) anti-HCV-positive patients were referred for further evaluation of hepatitis $\mathrm{C}$. They included $77 \%$ of the patients who were HCV RNA positive with elevated ALT and $39 \%$ of patients who were HCV RNA positive with normal ALT (Fig. 1).

Of the 20 patients who were HCV RNA positive with elevated ALT who were not referred for subspecialist care, a reason for not referring was documented in 14 patients: low efficacy/significant side effects of therapy (7), significant psychiatric comorbidity (4), and absence of symptoms related to hepatitis (3).

\section{Liver Disease in Group 1 Patients}

One hundred thirty nine (61\%) group 1 patients underwent further evaluation in the gastroenterology/hepatology clinics. The majority of the patients seen in subspecialty clinic had elevated ALT levels (78\%) and were viremic (87\%) (Table 3). Of the 30 patients with normal liver enzymes, 26 $(87 \%)$ had normal values on at least two occasions. Of the 18 patients who had undetectable hepatitis C RNA, 10 were retested and all remained PCR negative.

Fifty-seven patients underwent liver biopsies. All had detectable HCV RNA, 51 (90\%) had elevated ALT levels. Only $9 \%$ of these patients had no fibrosis, whereas $40 \%$ had bridging fibrosis or cirrhosis (Table 3 ).

\section{Compliance With Hepatitis C Screening Recommendations}

The majority of patients in all three groups had an initial visit after January 1, 1993: 93\%, 91\%, and 88\% in groups 1,
2, and 3, respectively. Less than $10 \%$ of patients in each group had documentation of being asked about both IDU and history of a blood transfusion before 1992-the two most common risk factors for hepatitis $\mathrm{C}$, during their initial visit (Table 4). Hepatitis $\mathrm{C}$ antibody testing was performed during the initial visit in 66 (29\%) group 1 and in $11(5 \%)$ group 2 patients. The vast majority (94\%) of group 1 patients tested during the initial visit had a known diagnosis of hepatitis $\mathrm{C}$.

During the initial visit, 66 (29\%) group 1 patients were asked about a history of IDU and 37 responded positive, 18 (8\%) were asked about a blood transfusion before 1992 with nine reporting yes. All the patients with an affirmative response to either of the above questions had a known diagnosis of hepatitis $\mathrm{C}$. When the patients with a previous diagnosis of hepatitis C were excluded, only 29 (13\%)

Table 3. Clinical Features of the 139 Hepatitis C Antibody (EIA)Positive Patients Referred to Gastroenterology/Hepatology Clinics

\begin{tabular}{lr}
\hline \multicolumn{1}{c}{ Clinical Features } & $\mathrm{n}(\%)$ \\
\hline ALT level & \\
Normal & $30(22)$ \\
Elevated & $109(78)$ \\
$1-2 \times$ ULN & $29(27)$ \\
$2-5 \times$ ULN & $69(63)$ \\
$>5 \times$ ULN & $11(10)$ \\
HCV RNA & $121(87)$ \\
PCR positive & $18(13)$ \\
PCR negative & \\
Histology (57 patients)* & $9(16)$ \\
No fibrosis & $21(37)$ \\
Minimal/portal fibrosis & $4(7)$ \\
Septal fibrosis & $8(14)$ \\
Bridging fibrosis & $15(26)$ \\
Cirrhosis & \\
\hline ULN $=$ upper limit of normal. & \\
$*$ None of the patients had clinical or biochemical evidence of hepatic decompen- \\
sation. All were viremic (HCV PCR positive), and 90\% had elevated ALT.
\end{tabular}


Table 4. Primary Care Physicians' Compliance With Hepatitis C Risk Factor Screening Recommendations During the Initial Visit*

\begin{tabular}{|c|c|c|c|}
\hline & Group 1 & Group 2 & Group 3 \\
\hline & $\begin{array}{c}\text { Anti-HCV+ } \\
\text { n (\%) }\end{array}$ & $\begin{array}{c}\text { Anti-HCV- } \\
\text { n (\%) }\end{array}$ & $\begin{array}{c}\text { Never Tested } \\
\mathrm{n}(\%)\end{array}$ \\
\hline \multicolumn{4}{|l|}{ Patient was asked about: } \\
\hline IDU & $66(31)$ & $36(17)$ & $53(26)$ \\
\hline Transfusion before 1992 & $18(8)$ & $5(2)$ & $7(3)$ \\
\hline History of acute hepatitis & $12(6)$ & $4(2)$ & $2(1)$ \\
\hline
\end{tabular}

* Patients with initial visit before January 1, 1993, were excluded.

patients were asked about IDU, and none was asked about blood transfusion before 1992 .

The charts of the index visit of group 3 patients were reviewed to assess the frequency in which hepatitis $\mathrm{C}$ risk factors were discussed during a routine office visit. Only two of $221(0.9 \%)$ patients had documented discussion of IDU or blood transfusion history.

\section{DISCUSSION}

Hepatitis C is a major health problem in the United States with significant medical, economic, and social consequences. Given the impact of this disease, the role of primary care physicians as gate-keepers in the U.S. health care system, and concerns about suboptimal care raised in previous surveys, this study was undertaken to determine the actual care hepatitis $\mathrm{C}$ patients receive in primary care clinics.

The initial visit to a primary care clinic is generally considered to be the most thorough visit. During this visit, the physician obtains a detailed history of current and past medical history as well as family and social history that may predispose the patient to certain medical illness(es). In this study, we found that less than $10 \%$ of patients attending a primary care clinic were asked about the two most common risk factors for hepatitis $\mathrm{C}$ during their initial visit, and less than $15 \%$ of anti-HCV test was ordered because of physician-identified risk factors. Our findings suggest that hepatitis C may be grossly underdiagnosed in primary care clinics. Failure to recognize and test patients who are at risk may lead to delays in diagnosis and treatment.

We acknowledge that our study was based on retrospective chart review of documented risk factor inquiry. It is possible that inquiries were made but not recorded. It is also possible that primary care physicians are overwhelmed by the long list of diseases (HIV infection, sexually transmitted disease, cancers, coronary artery disease, etc) for which risk factors should be inquired; therefore, omissions are inevitable. Because of time constraints in busy clinics, inclusion of risk factors for hepatitis $\mathrm{C}$ in a standardized intake questionnaire may improve the rate of identification of hepatitis $\mathrm{C}$ patients in primary care clinics. Self-administered questionnaires are also less confrontational and may yield more reliable answers on sensitive issues such as history of IDU. In this study, we found that none of the 29 group 1 patients who were not known to have hepatitis $\mathrm{C}$ responded yes when asked about history of IDU during their initial visit. Although some of these patients may have acquired hepatitis $\mathrm{C}$ through other routes, it is possible that answers to casual direct inquiry may be inaccurate. A review of the intake questionnaires used in our health care system demonstrated that only one of seven that are currently used included questions on risk factors for hepatitis C. Our results show that if the diagnosis of hepatitis $\mathrm{C}$ is to be based on testing at-risk individuals, this expectation is currently not met.

The majority of anti-HCV-positive patients had been tested for ALT level before or on the day of hepatitis C testing. Of the remaining patients, one-third did not have ALT testing up to $1 \mathrm{yr}$ after they were known to be anti$\mathrm{HCV}$ positive. Because of the correlation between abnormal ALT and referral to a subspecialist, and the potential impact of ALT level on decisions regarding liver biopsy and treatment, initial evaluation of liver disease such as assessing liver biochemistry should be initiated in the primary care clinic. Half of the patients with detectable HCV RNA and normal ALT had no further ALT testing or referral. The 1997 National Institutes of Health Consensus Statement on Hepatitis C did not recommend liver biopsy or treatment for hepatitis $\mathrm{C}$ patients with normal ALT level except in the context of clinical trials (2). However, hepatitis C patients may have fluctuating ALT levels, and $30 \%$ of hepatitis C patients with persistently normal ALT levels have histological evidence of liver disease (13). In light of the significant improvement in efficacy of hepatitis $\mathrm{C}$ treatment in recent years, we recommend that referral for further evaluation be considered for all patients who are HCV RNA positive regardless of their ALT levels.

Although the main focus of this research was to determine the actual level of care hepatitis $\mathrm{C}$ patients receive in primary care clinics, we were also able to gather significant information on the spectrum of liver disease in these patients. The majority of anti-HCV-positive patients was viremic and had elevated ALT levels. Despite the absence of symptoms, $40 \%$ of the patients who underwent liver biopsy had bridging fibrosis or cirrhosis. We acknowledge that only 
a minority of the patients in this study underwent liver biopsy, and there is a possibility of selection bias. However, it is worth noting that even if we use the entire cohort of anti-HCV-positive patients as denominator, our results still show that at least $10 \%$ (23 of 229) of anti-HCV-positive patients presenting to a primary care clinic had advanced liver disease at the time of diagnosis.

In summary, we found that hepatitis $\mathrm{C}$ testing in primary care clinics is seldom initiated because of physician-identified risk factors. Our study also showed that less than $10 \%$ patients were asked about hepatitis $\mathrm{C}$ risk factors during the initial visit to their primary care physicians. We recognize that there are limitations in our study, and our observations may not be generalizable to other health care systems in this country or in other countries. Nevertheless, our findings suggest that more effective mechanisms must be developed to identify individuals who are at risk for hepatitis $\mathrm{C}$ to ensure early diagnosis and intervention. Early diagnosis is important as our data suggest that at least $10 \%$ of patients had advanced liver disease despite the absence of symptoms. Once the diagnosis of hepatitis $\mathrm{C}$ was made, most patients in this study had appropriate initial evaluation and referral. Simple algorithms designed for primary care physicians with regular updates may further improve counseling, initial evaluation, and referral such that care of hepatitis $\mathrm{C}$ patients may be optimized without overburdening health care resources.

Reprint requests and correspondence: Anna S. F. Lok, M.D., Division of Gastroenterology, University of Michigan Hospital, 3912 Taubman Center, Box 0362, Ann Arbor, MI 48109-0362.

Received Apr. 3, 2002; accepted Aug. 1, 2002.

\section{REFERENCES}

1. Alter MJ, Kruszon-Moran D, Nainan OV, et al. The prevalence of hepatitis C virus infection in the United States, 1988 through 1994. N Engl J Med 1999;341:556-62.

2. Powell DW, for the Hepatitis C Consensus Development Panel. National Institutes of Health consensus development conference panel statement: Management of hepatitis C. Hepatology 1997;26(suppl 1):2S-10S.

3. Wong JB, McQuillan GM, McHutchinson JG, Poynard T. Estimating future hepatitis C morbidity, mortality and costs in the United States. Am J Public Health 2000;90:1562-9.

4. Wiley TE, McCarthy M, Breidi L, et al. Impact of alcohol on the histological and clinical progression of hepatitis $\mathrm{C}$ infection. Hepatology 1998;28:805-9.

5. Centers for Disease Control and Prevention. Recommendations for prevention and control of hepatitis C virus (HCV) infection and HCV-related chronic disease. MMWR 1998;47: $1-39$.

6. Manns MP, McHutchison JG, Gordon SC, et al. Peginterferon alfa- $2 b$ plus ribavirin compared to interferon alfa- $2 b$ plus ribavirin for the treatment of chronic hepatitis C: 24-week treatment analysis of a multicenter, multinational phase III randomized controlled trial. Hepatology 2000;32:552A (abstract).

7. Fried MW, Shiffman ML, Reddy KR, et al. Pegylated (40 $\mathrm{kDa}$ ) interferon alfa-2a (Pegasys) in combination with ribavirin: Efficacy and safety results from a Phase III, randomized, actively controlled, multicenter study. Gastroenterology 2001; 120(suppl 1):289A (abstract).

8. McHutchison JG, Gordon SC, Schiff ER, et al. Interferon alpha-2b alone or in combination with ribavirin as initial treatment for chronic hepatitis C. N Engl J Med 1998;339: 1485-92.

9. Poynard T, Marcellin P, Lee SS, et al. Randomized trial of interferon alpha2b plus ribavirin for 48 weeks or for 24 weeks versus interferon alpha2b plus placebo for 48 weeks for treatment of chronic infection with hepatitis C virus. Lancet 1998; 352:1426-32.

10. Shehab TM, Sonnad SS, Jeffries M, et al. Current practice patterns of primary care physicians in the management of patients with hepatitis C. Hepatology 1999;30:794-800.

11. Nicklin DE, Schultz C, Brensinger CM, Wilson JP. Current care of hepatitis $\mathrm{C}$ patients by primary care physicians in an integrated delivery system. J Am Board Fam Pract 1999;12: 427-35.

12. Shehab TM, Sonnad S, Lok ASF. Management of hepatitis C patients by primary care physicians: A nationwide survey. Hepatology 1999;30:209A (abstract).

13. Healey CJ, Chapmann RWG, Fleming K. Liver histology in hepatitis $\mathrm{C}$ infection: A comparison between patients with persistently normal and abnormal transaminase. Gut 1995;37: 274-8. 